\title{
Induzierte pluripotente Stammzellen: Ruhe an der Ethikfront?
}

\author{
Bettina Schöne-Seifert
}

Online publiziert: 14 . Oktober 2009

(C) Die Autor(en) 2009. Dieser Artikel ist auf Springerlink.com mit Open Access verfügbar.

Seit gut zehn Jahren sorgt die Stammzellforschung international für Aufregung: Auf wissenschaftlichem Terrain liefert sie fundamentale zellbiologische Erkenntnisse und weckt hochgesteckte Hoffnungen, eines Tages „maßgeschneiderte“ Ersatzzellen für die Behandlung von Patienten etwa mit großen Herzinfarkten, schwerem Diabetes oder Querschnittslähmung herstellen zu können. Auf ethischem Terrain sorgt sie für anhaltend heftige Debatten über die Frage, ob für diese Forschung sehr frühe menschliche Embryonen verwendet werden dürfen, galten doch die aus diesen gewonnen sogenannten ES-Zellen bis vor kurzem als die vielversprechendsten, die ,echten“ Alleskönner-Zellen. In Deutschland hat der Gesetzgeber, aus ethischen Gründen, die Herstellung von ES-Zellen unter Strafe gestellt - unabhängig davon, ob die dafür geopferten Embryonen in der Fortplanzungsmedizin ,übrig“ geblieben oder durch Forschungsklonen hergestellt worden wären. So bleibt deutschen Forschern nur die Hintertür, ES-Zellen unter strikten Auflagen aus dem Ausland einzuführen. Aufregungspotential hat auch diese Regelung.

2009 nun ist wissenschaftlich wie ethisch ein besonders aufregendes Jahr für die Stammzellforschung, indem es maßgebliche Erfolge in der seit etwa 3 Jahren entwickelten Reprogrammierungstechnik beschert, also in der Rückführung spezialisierter Körperzellen in ein Alleskönner-Stadium. Schlag auf Schlag erscheinen 2009 in den weltbesten Fachzeitschriften Arbeiten, die berichten, wie sich Körperzellen von Mäusen und Menschen auf immer „bessere“ Weise reprogrammieren lassen: Schleuste man dafür bisher mehrere Gene in die Ausgangszellen ein und beließ sie dort, reicht nun ein einziges Gen; reicht ein vorübergehender Geneinbau; reicht nun gar das Einbringen bestimmter Trigger-Proteine. Die mit diesen Tricks aus Haut-, Bauchfett- oder Nervenzellen produzierten ,induzierten pluripotenten Stammzellen“ (iPS-Zellen) versprechen, für das gezielte Heranzüchten spezialisierter Zelllinien ebenso geeignet zu sein wie ES-Zellen. Bisher hat es hier keine Enttäuschungen gegeben - wenngleich man ES-Zellen zunächst weiterhin als Goldstandard wird einsetzen wollen.

B. Schöne-Seifert $(\square)$ Institut für Ethik, Geschichte \& Theorie der Medizin, Universität Münster, Von-Esmarch-Str. 62 48149 Münster, Deutschland E-Mail: bseifert@uni-muenster.de 
Darüber hinaus haben iPS-Zellen - wenn man an mögliche Behandlungen denkt - den Vorteil, aus leicht zugänglichen Körperzellen der Patienten herstellbar und immunologisch verträglich zu sein. Dass sich Reprogrammierung nun auch mit Proteinen bewerkstelligen lässt, räumt zudem ein erhebliches therapeutisches Hindernis aus dem Weg: die Gefahr nämlich, durch das Einschleusen von Genmaterial ungewollte genetische Veränderungen der Zellen auszulösen und so etwa das Risiko von Krebsentstehung zu erhöhen.

Was lässt sich dazu aus ethischer Sicht sagen? Zunächst einige unstrittig positive Befunde: Die skizzierten Fortschritte bekräftigen die Hoffnung, mit Stammzellen eines Tages wirklich Krankheiten heilen zu können, die bisher als unbehandelbar gelten. Und dies vielleicht gar schneller als zunächst angenommen. Was für einen Segen das für zahllose Kranke und deren Angehörige bedeuten könnte, lässt sich kaum ausmalen. Dass diese Entwicklungen bereits jetzt tröstlich für die vielen Forscher sind, denen man vorgeworfen hat, einmal mehr einen bloßen hype zu produzieren, lässt sich indes leichter vorstellen. Es ist dies wohl auch kein schlechtes Antidot gegen die allgemeine Forschungsskepsis, die derzeit in Deutschland europäische Rekordhöhe verbucht. Bemerkenswert ist zudem das Ausmaß internationaler Kooperation auf dem Stammzellsektor, wo zwischen den Top-Labors nicht nur gewetteifert wird, sondern Mitarbeiter ausgetauscht und neue Ansätze gemeinsam konzipiert werden. Eine der diesjährigen „Durchbruchs-Arbeiten“ entstand beispielsweise in Zusammenarbeit von Wissenschaftlern aus den USA und aus Münster [4].

Strittig ist die Frage, ob der Ersatz von ES-Zellen durch iPS-Zellen - sollten sich diese wirklich in allen relevanten Hinsichten verhalten wie jene - selbst ein ethischer Durchbruch ist. Wer das Opfern menschlicher Embryonen im Sechs-Tage-Stadium, wie es die Gewinnung von ES-Zellen erfordert, moralisch unzulässig findet, wird hier ja sagen, und umgekehrt. ja werden auch diejenigen sagen, die ethische Probleme bei der Alternative des Forschungsklonens sehen: sei es bei der Eizellspende (einem gender-Problem), sei es bei der Verwendung tierischer Eihüllen. ja sagt schließlich auch, wer die ethisch motivierte Kritik der Embryonenschützer nicht teilt, aber in die ethische Waagschale wirft. Die neuen ethischen Stammzellen - embryo-free und gender-neutral -, wie UK-Bioethiker John Harris es ironisch auf den Punkt bringt [3], sind also, so sie sich endgültig bewähren, je nach Perspektive ein Meilenstein beim Beenden einer unethischen Forschungspraxis oder jedenfalls bei der Umgehung ethischer Dispute.

Doch für die entscheidende Grundfrage, die Frage nach dem normativen Status früher Embryonen, ist die iPS-Zell-Botschaft vielleicht eine ganz andere. Für diejenigen, die hier um Einsicht und Konsistenz ringen, kann die Umgehungsstrategie nicht das Ende der Debatte sein - im Gegenteil. In aller Knappheit: Die Reprogrammierungserfolge bestätigen die These von der prinzipiellen Verwandelbarkeit aller Zellarten in alle anderen - insbesondere aller Körperzellen in iPS-Zellen. Diese Reprogrammierung könnte auch einen (in der Regel unerwünschten) Schritt weitergehen: zurück zu einer Zelle, die sich genau so verhält wie eine befruchtete Eizelle, also wie ein ganz früher Embryo - man könnte sie dahin ,triggern“. Was heißt das für das Zentralargument des Embryonenschutzes, Embryonen hätten deswegen denselben moralischen Status wie geborene Menschen, weil sie das Potential hätten, zu solchen zu werden?

Jede Körperzelle hat offenbar das Potential (realisierbar durch gentechnisches oder biochemisches „Triggern“), zu einer Zelle zu werden, die ihrerseits das Potential hat (realisierbar durch Interaktion mit einem reproduktionsbereiten mütterlichen Organismus), zu einem lebensfähigen Menschen zu werden. Dass biochemische Tricks „künstlich“, Schwangerschaften hingegen „natürlich“ sind, ist unbestreitbar. Aber kann dieser Unterschied ethisch etwas ausrichten? Wie? Das Potentialitätsargument scheint zumindest auf eigenen Füßen nicht mehr gut stehen zu können. Auch das ist aufregend [1-3]. 
Open Access Dieser Artikel unterliegt den Bedingungen der Creative Commons Attribution Noncommercial License. Dadurch sind die nichtkommerzielle Nutzung, Verteilung und Reproduktion erlaubt, sofern der/die Originalautor/en und die Quelle angegeben sind.

\section{Literatur}

1. Ach JS, Siep L, Schöne-Seifert B (2006) Totipotenz und Potentialität: Zum moralischen Status von Embryonen bei unterschiedlichen Varianten der Gewinnung humaner embryonaler Stammzellen. Jahr Wiss Ethik 11:261-321

2. Baertschi B, Mauron A (2008) Moral status revisited: the challenge of reversed potency. Bioethics. doi:10.1111/j.1467-8519.2008.00686.

3. Chan S, Harris J (2008) Adam's fibroblast? The (pluri)potential of iPCs. J Med Ethics 34(2):65-66. doi:10.1136/jme.2007.023937

4. Zhou $\mathrm{H}$ et al (2009) Generation of induced pluripotent stem cells using recombinant proteins. Cell Stem Cell 4(5):381-384. doi:10.1016/j.stem.2009.04.005 